\title{
TOWARD A GLOBAL OCEAN ECOSYSTEM MID-TROPHIC AUTOMATIC ACOUSTIC SAMPLER (MAAS)
}

\author{
Nils Olav Handegard ${ }^{(1)}$, David A. Demer ${ }^{(2)}$, Rudy Kloser $^{(3)}$, Patrick Lehodey $^{(4)}$, Olivier Maury ${ }^{(5)}$, Yvan Simard ${ }^{(6)}$ \\ (1) Institute of Marine Research, P.O. Box 1870 Nordnes, 5817 Bergen, Norway, Email: nilsolav@imr.no \\ (2) National Oceanic and Atmospheric Administration's Southwest Fisheries Science Center, 3333 North Torrey Pines \\ Court La Jolla, CA 92037-1022, USA, Email: David.Demer@noaa.gov \\ (3) CSIRO (Commonwealth Scientific and Industrial Research Organisation) - Marine and Atmospheric Research, \\ PO Box 1538, Hobart 7001, Australia, Email: rudy.kloser@csiro.au \\ (4) CLS (Collecte Localisation Satellites), MEMMS (Modélisation des Ecosystèmes Marins et Monitoring par Satellites), \\ Département Océanographie Spatiale, 8-10 rue Hermès, 31520, Ramonville, France. Email: PLehodey@cls.fr \\ ${ }^{(5)}$ Institut de Recherche pour le Développement, France, Email: Olivier.Maury@ifremer.fr \\ (6) Fisheries and Oceans, Canada, Maurice Lamontagne Institute, 850 Route de la Mer, Mont-Joli, \\ Québec G5H $3 Z 4$ Canada; Institute of Marine Sciences, University of Québec at Rimouski, \\ 310 Allée des Ursulines, Rimouski, Québec G5L 3A1, Canada, Email: Yvan.Simard@dfo-mpo.g.ca
}

\begin{abstract}
Despite their huge biomass and pivotal role, the midtrophic levels of marine ecosystems are not generally subject to systematic monitoring. Data from such monitoring is crucial for parameterizing, validating, and constraining numerical models of mid-trophic communities. In recent years, acoustic sampling technology has matured, and we argue that acoustic sampling technology, due to long-range propagation in water, is the only means to efficiently observe the large biomass of the mid-trophic levels at ecologically important temporal and spatial scales. We argue that it is timely to propose a collaborative effort to utilize these new techniques, and we propose to widely deploy automated acoustic recorders, using a variety of platforms, to achieve this goal. Without such large-scale coordinated monitoring, we will continue to lack an understanding of how the effects of climate variability are mediated from primary production up to the higher trophic levels and, conversely, how changes in higher trophic levels may affect the lower trophic levels.
\end{abstract}

The objective of the MAAS (Mid-Tropic Automatic Acoustic Sampler) project is, therefore, to provide nearreal-time global-scale monitoring of mid-trophic-level organisms.

\section{BACKGROUND}

Mid-trophic level organisms, including meso-zooplanktonic and micro-nektonic prey, are essential components of the pelagic ecosystems. These components are crucial for understanding the propagation of climatic and lower trophic biophysical changes to the upper trophic levels, and for the topdown control of planktonic systems involved in biogeochemical cycles, such as $\mathrm{CO} 2$ fixation and export.
Biological observations of the upper and mid trophic levels are usually obtained using scientific vessels equipped with appropriate observation tools combined with commercial catch sampling and landings data. This strategy is expensive, and surveys are generally conducted sporadically or on an annual basis in restricted regions. Their limited spatial-temporal coverage seriously limits their usefulness for large-scale ecosystem models. Physical observations, on the other hand, are now gathered continuously on a global scale using a combination of automated oceanic moorings, drifters, gliders, and ships of opportunity and data are transmitted to the users through satellite-based links. Such technologically advanced observing systems have been evolving together with advanced oceanic models and they now collectively constitute major contributions to improved understandings and forecasting of the dynamics of the ocean from regional to global scales. We propose a similar approach for the higher trophic levels, in particular the mid trophic level

The mid-trophic level is an important compartment of marine ecosystems. The oceanic fisheries initially impact the highest trophic levels of marine ecosystems, but there is an increasing concern about the potential cascading effects from the removal of predators [1]. From a bottom-up perspective, environmental variability determines phytoplankton and zooplankton abundance and distribution, and then leads to important effects on larvae and juveniles of predators as well as on their forage species, leading to large variability in abundances and distributions of species with major economic value. For example, climate-related changes in large-scale oceanic conditions, like those due to the El Niño Southern Oscillation in the Pacific and Indian Oceans or the North Atlantic Oscillation in the Atlantic Ocean, strongly influence the habitat, prey, and population dynamics of tuna and other large predator species. There is a need to increase our observing capabilities for these trophic levels. 
During the last two decades, models have been expanded to represent more aspects of the ocean interior, including low-trophic levels (i.e. phytoplankton and zooplankton) and, more recently, mid-trophic-levels (i.e. micro nekton including small fish, crustaceans, squids and gelatinous organisms [2-4]). However, a major bottleneck to such model development is the lack of a routine, cost effective, basin-scale observation network which would provide foundation to these models on the processes controlling the abundances, distributions, and vertical movements of mid-trophic level organisms.

The need for implementing global observing systems for marine biodiversity is urgent in the present global change era [5] and it has become a priority for international organizations like GEO (Group on Earth Observation), GOOS (Global Ocean Observing System) or the proposed GEOBON (Group on Earth Observations Biodiversity Observation Network [6]). Large scale international programs on marine biodiversity such as CoML (Census of Marine Life) [7] have been deploying such observing systems focusing on both low trophic levels (e.g. ICoMM (International Census of Marine Microbes) for bacteria) and high trophic levels (e.g. TOPP (Tagging of Pacific Predators and OTN (Ocean Tracking Network) for top predators) but no large scale project exist to date for the synoptic observation of mid-trophic levels in marine ecosystems, despite their pivotal role between biogeochemistry (/climate) and ecosystems (/fisheries). GLOBEC (Global Ocean Ecosystem Dynamics) and IMBER (Integrated Marine Biogeochemistry and Ecosystem Research Project), the two marine ecosystem programs in The International Geosphere-Biosphere Program operating in the Earth System Science Partnershipframework, are entering into a merging process. During this process the need for a global mid-trophic observing system such as the MAAS project has been strongly and explicitly emphasized [8]. The MAAS (Mid-Tropic Automatic Acoustic Sampler) project has been officially endorsed by the CLIOTOP (CLimate Impacts on Oceanic TOp Predators) Program [9] as a major challenge for the coming years and a MAAS task force has been formed to study the technical aspects of the project (see http://www.globec.org/index.php?id=62).

It is now technically possible to adopt the approach which has been used with great success by oceanographers for the mid-trophic levels organisms. Further to the physical sensors (e.g. conductivity, temperature and depth) that are the common to present observational systems, new systems should be equipped with acoustic sensors for detecting, identifying, and quantifying marine organisms. These systems are capable of detecting organisms in the size range 0.1 to $100 \mathrm{~cm}$. This size range covers major meso-zooplanktonic and micro-nektonic taxonomic groups which link primary production to higher trophic levels, but whose biomasses are poorly documented at present. Data can be obtained at basin scales using an integrated sampling and measurement-platform strategy including moorings, ships of opportunity, ocean drifters, AUVs (Autonomous Underwater Vehicles), gliders, landers, and sea ice, communicating using cables, acoustic modems, radio ethernet and satellite telephone.

Technically, the system should be easy to operate and should allow continuous data collection to resolve the temporal dynamics of the ecosystem. A compressed data stream could be provided continuously by one or more echosounders, or a wideband system, through a satellite connection. A multiple-frequency approach would provide important extra functionality to the data such as separation and identification of major fauna categories (e.g. fish vs. zooplankton) and their size in the water column. The data could be transmitted via satellite at regular time intervals, together with the GPS position, and rapidly integrated in current ecosystem multivariate observatories and models.

\section{The MAAS initiative has the following overarching goal: To develop observational platforms equipped with multi-frequency acoustics to provide data for identification and quantification of marine life on a global scale, and to reliably transfer data to the users. To simultaneously develop routines and protocols to include and/or assimilate these data into an existing and future model frameworks and thus demonstrate an application in ecosystem-based assessments and ecosystem state tracking.}

Eventually, such an acoustic system for observing midtrophic levels could be implemented to nodes of fixed observatory networks such as ESONET (European Seas Observatory NETwork) (http://www.esonet-emso.org/). These goals are complementary to or supportive of CoML. This initiative would also fit well with the European activities associated with MERSEA (Marine Environment and Security for the European Area), EUROCEANS (European network of excellence for Ocean Ecosystems Analysis), HERMES (Hotspot Ecosystem Research on the Margins of European Seas) and International Argo (Global array of free-drifting profiling floats).

\section{STATE-OF-THE-ART}

\subsection{Acoustic remote sensing of mid trophic levels}

The first remote sensing of physical properties of the ocean was the lead-line, used for mapping bottom depth and bottom substrate for navigational purposes. Later, fishers observed that the same principle could be used to detect and quantify schools of fish, and acoustics has been a tool for fish studies since the 1930s [10]. This 
gave the observers a very direct "contact" with the ocean interior. Some countries started routine acoustic monitoring of the state of fish stocks about 1970 and presently acoustics is used worldwide for fish resource assessment and management purposes. Modern techniques give far better coverage and quality of data.

Further, acoustic sensing of the ocean to include biological components beyond plankton is the only method available to sample at large spatial and temporal scales with high resolution, without artificial lighting, and capable of observing at both small [11] and large scales [12]. Estimate of surface primary productivity can be derived at large spatial and temporal scales using ocean colour from satellite imagery with appropriate ground truthing and algorithms. In the same way, acoustic methods have been developed to provide estimates of mid-trophic organism distribution and abundance at ocean basin (micro nekton $\sim 2$ to $20 \mathrm{~cm}$ ) (Fig. 1). These estimates of mid-trophic organism distribution, abundance and vertical flux over time are needed for the development of ecosystem models that link physics to fish and other higher top predators [13 and 14] and have to track exchanges between the atmosphere and the deep ocean.

Acoustic categorization through multi frequency data analysis has made substantial progress in recent years [15]. Combined with more traditional morphological measures of schools and individuals as well as behavioural characterization of individuals and clusters of marine life, an observation system facilitates interesting categorization possibilities (Fig. 2). For a buoy or a stationary observatory, the number of frequencies is limited by the available power supply. However, with only two frequencies, fish and zooplankton should be separable due the different scattering properties. Where the smaller organisms still follow a Rayleigh type scattering, the larger biota may follow geometrical scattering enabling separation by two frequencies.

Present observation of marine resources and their biological environment is to a large extent dependent of research vessel capacity, and monitoring is often done through scientific surveys [16] and [17]. These surveys give quality synoptic snap-shots of the status at a certain time but lack temporal dynamics, which is known to significantly imprint the functioning of the ecosystems. Further, these surveys suffer from being national or international on a local scale. As an example, using ships of opportunity (research, fishing vessels etc.) with current technology and methodology, it is now possible to provide ocean basin scale coverage similar to the successful ship of opportunity expendable bathy- thermograph network (Fig. 2). In recent years new acoustic autonomous systems, stationary and drifting, have been tested and are giving genuinely new information [18-21] (Fig. 3).
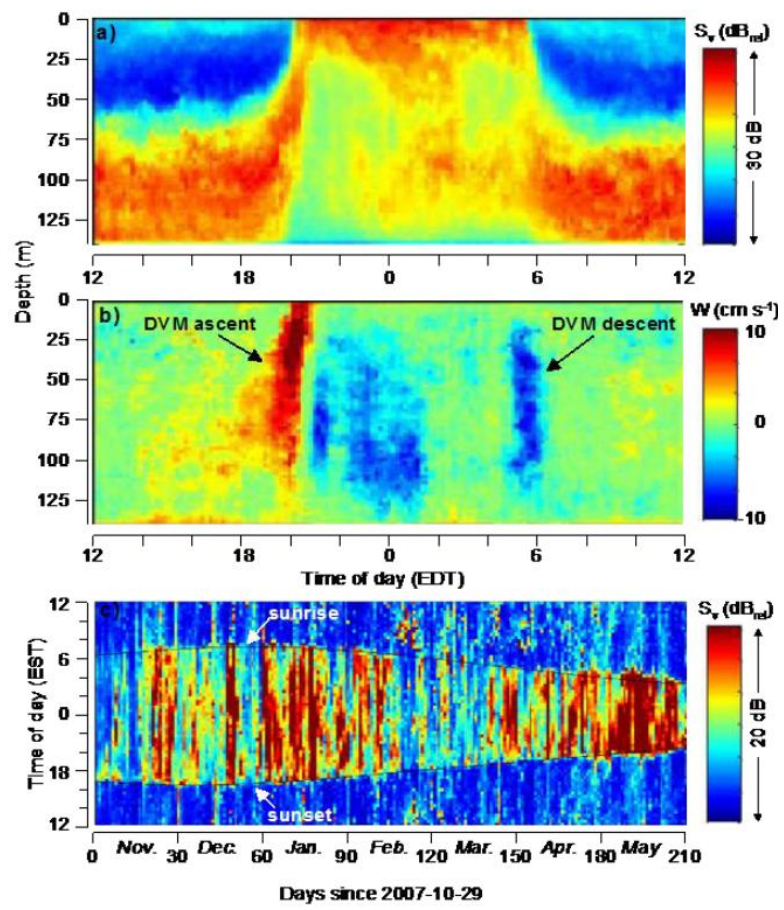

Figure 1. Example of the tracking of Diel Vertical Migration (DVM) of a krill aggregation in St. Lawrence using the acoustic backscatter data from a $300 \mathrm{kHz}$ Acoustic Doppler Current Profiler (ADCP) for the month of august 2004 (a: biomass index Sv, b: median vertical swimming speed index from [13]) and over 7 months of the year, including under-ice periods during winter (c; constructed from daily median Sv for the 10$30 \mathrm{~m}$ depth interval).

\subsection{Technology}

Some of the technological challenges need to be realized for successfully moving from vessel-based annual surveys to observing systems with increased temporal and spatial resolution. These objectives can be achieved today, but often with large, power intensive and expensive equipment. Further, they are often limited to particular purposes and not designed for longterm operation and data communication. There is also a need to adjust models to fit with the nature of acoustics data, enabling us to fully utilize the advantages of acoustic data. The technology and methodological challenges, as we see it, are three-fold: hardware technology; data handling and processing; and communication. 

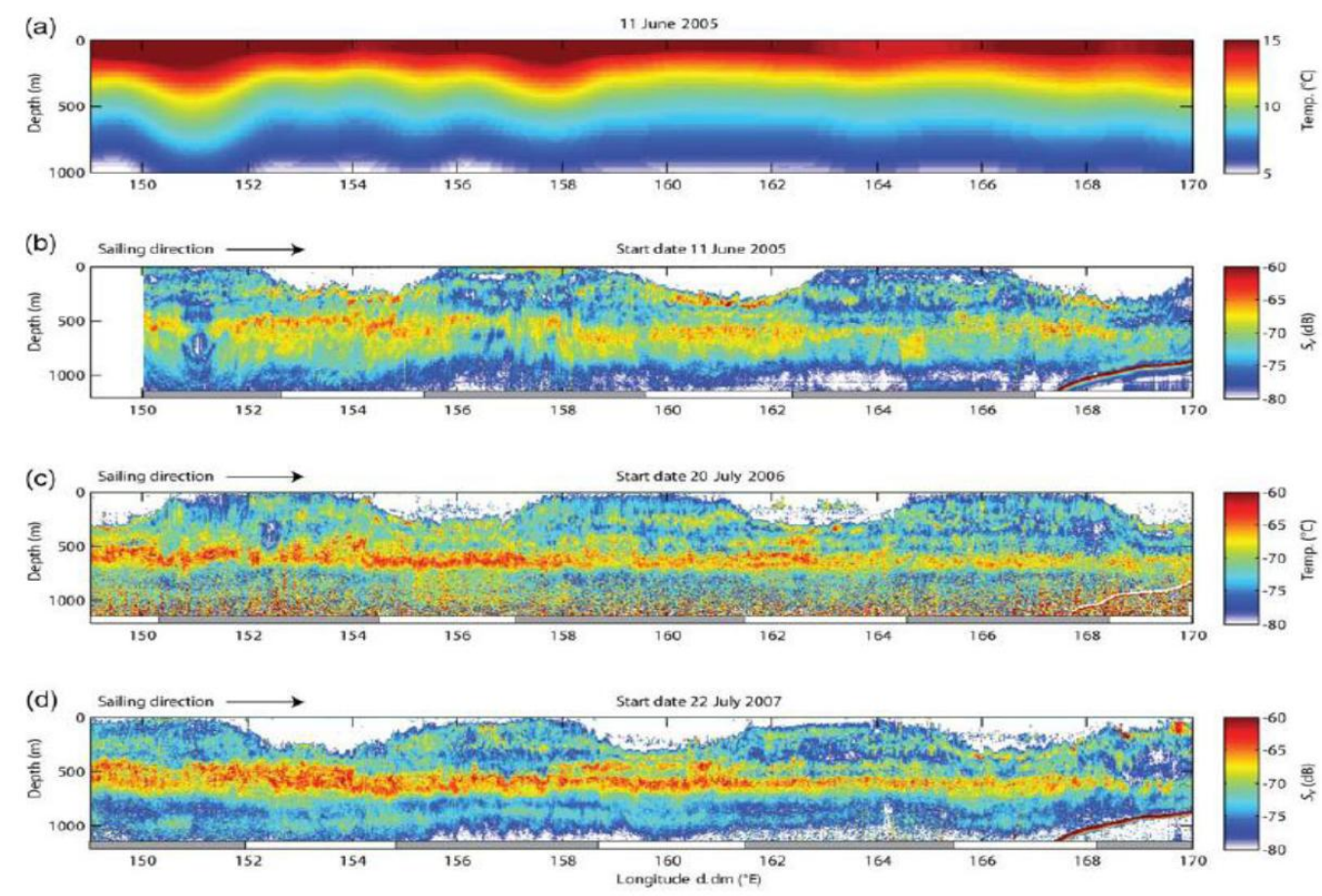

Figure 2. Demonstration of basin scale distribution and abundance of mid-trophic organisms provided by calibrated ships of opportunity (fishing vessels) over multi year time frame using well established standardized technologies and methodologies (Fig. 4 from [22]). These basin scale snapshots provide information for ecosystem model parameterization, data assimilation and as an ecological indicator of change in the deep scattering layer over basin scales. Implementation of this method is very cost effective and forms a component of the necessary global coverage.

\subsection{Hardware}

By combining state of the art components, we expect to establish a compact package of technology. The feasibility is demonstrated in e.g. moored Acoustic Doppler Current Profilers [23] (Fig. 4). The system could be modularized into programmable echo sounder, power, and communication modules. Thus, the system can be modified according to the area of operation and focus of study. For example, for a drifting system a simple extension of lifetime in sunny areas can be obtained by producing electricity with a solar panel. Further, for drifting systems in areas where recovery is anticipated, more data can be collected and transferred given that the batteries and high-density data storage can be changed regularly.

\subsection{Data handling and processing}

Echosounders collect data on time scale of seconds and vertical resolution of $\mathrm{cm}$ creating a very large data stream (on the order of $5 \mathrm{MB}$ per hour at dualfrequencies). If the platform is not retrieved, e.g. for drifting disposable buoys, the data needs to be transferred via satellite. It is today not possible to transfer raw data via satellite, and at least two potential solutions exist. First, compression routines such as runlength-encoding (RLE) that compare consecutive similar pings and keep a minimum of data without losing essential information could be developed. Second, establishing new compression routines for acoustic data that compress the ping information to a minimum or metrics summarizing the information by bins before satellite transfer is feasible. Protocols can be developed with a focus for the particular aspects essential for model development (e.g. summaries of deep scattering layer depth, and intensity, etc). This approach has been used with success when combining an acoustic listener to an Argo float [24].

Further, the links to the models are required. The excellent vertical resolution provided with acoustics may allow categorization utilizing the different diurnal behaviour for different species groups (e.g. Figs. 3 and 5) [25]. However, to further proceed along these lines, we need data from a prototype network for feeding realistic simulations to address the adequate sampling intensity, taking into account the characteristics of the observed patchy distributions. There are currently several efforts to address this challenge, but we believe a stronger collaboration is required to make significant progress. 


\subsection{Communication}

Depending on the platform, various communication solutions may exist. Vessels of opportunity may submit data via wireless network while in dock, or even summary statistics via satellite (c.f. previous section). That approach will be especially relevant for buoys systems that are not recovered. Various transfer approaches could be tried and the necessary development done to optimize transfer of data.
Decompression routines on the user end will reestablish the data as close as possible to the originally collected information. We also envision a central data storage unit to hold all these data in an easily accessible data structure, as this is already operational for cabled ocean observatories such as VENUS (Victoria Experimental Network Under the Sea), NEPTUNE (North East Pacific Time-series Undersea Networked Experiments and ESONET.
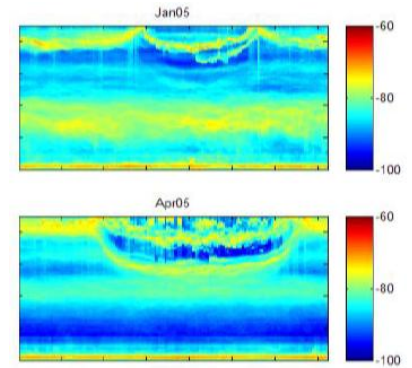

Aug04

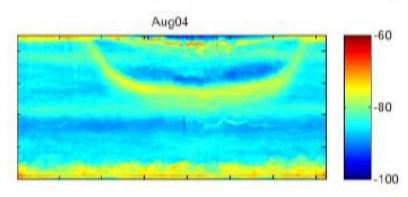

Novo4

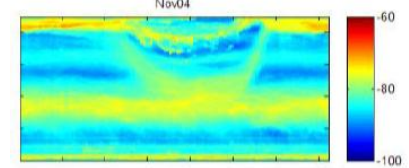

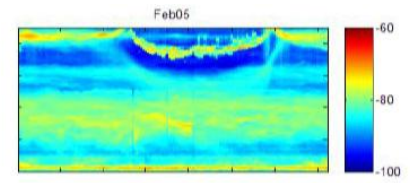

Mayos

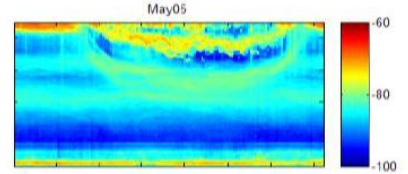

Sep04

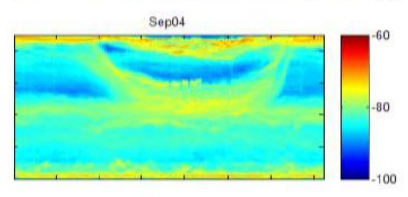

Dec04

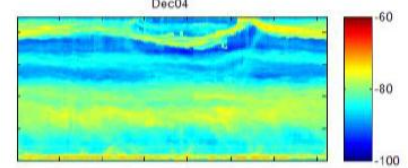

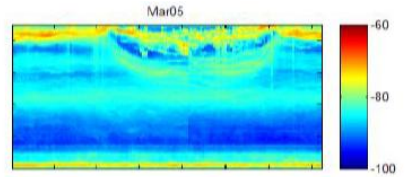

Ju104

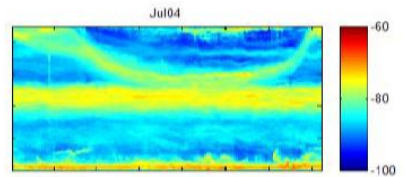

at04

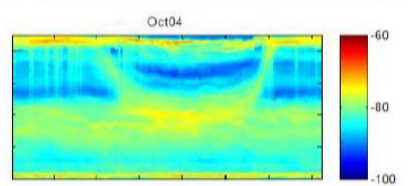

Figure 3. Monthly-mean echograms from the MarEco buoy deployment at the Mid-Atlantic ridge (position $51031.6 \mathrm{~N}$ $30019.9 \mathrm{~W}$ ) during an 11-month deployment. The diel migration is easily seen from the echograms. The idea is to separate the backscatter into different functional groups based on these patterns.

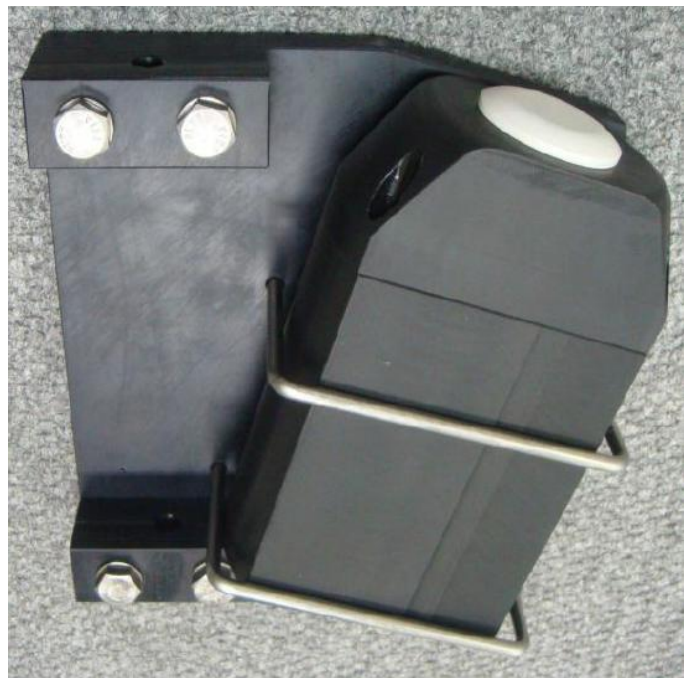

Figure 4. The EchoTag, example of a 190-kHz singlebeam echosounder and temperature logger that can be mounted on moorings, and capable of delivering profiled volume backscattering strength from its location at $150 \mathrm{~m}$ to the sea surface for durations of greater than one year.

\subsection{Models}

Several simple metrics tracking zooplankton and micro nekton components of the ecosystem can easily be defined. These variables can be analyzed with other biophysical variables using various multivariate time-series analysis schemes. Among them are profiles of biomass concentration, size and taxa composition, vertical movements and flux.

At least two modelling approaches of the Mid-Trophic Level (MTL) organisms exist, that can be already used to assimilate acoustic data. The first one is based on size-structure and energy flow [4]. This model incorporates details in physiology derived from the Dynamic Energy Budget theory [26], with spatial dynamics based on a system of advection-diffusionreaction (ADR) equations that take into account ocean circulation. A different approach is used in the Spatial Ecosystem And POpulation DYnamics Model (SEAPODYM), initially developed to describe the spatial age-structured population dynamics model of large oceanic predators [27]. The SEAPODYM-MTL component is based on an ADR system of equations, 
and it describes several functional groups following a temperature-linked time development relationship [3].

A first collaborative 2-year project between the Marine Ecosystem Modelling and Monitoring group (CLS (Collecte Localisation Satellites), France) and the Pacific Islands Fisheries Science Center (NMFS (National Marine Fisheries Service), Hawaii, USA) has been funded recently by the Pelagic Fisheries Research Program (JIMAR (Joint Institute for Marine and Atmospheric Research), Univ. of Hawaii, USA) to initiate the work required for assimilating in situ bioacoustics data in the SEAPODYM-MTL model. The functional groups in SEAPODYM-MTL are based on the occurrence of diel migration between the epipelagic, mesopelagic and bathypelagic layers, or the lack thereof (Fig. 5). Recruitment, ageing, mortality and passive transport with horizontal currents are modelled by a system of $\mathrm{ADR}$ equations, taking into account the vertical behaviour of organisms.

Since the dynamics is represented by the established relationship of temperature-linked time development, there are only six parameters in the model that have to be estimated. The first one (E) defines the total energy transfer between primary production and all the MTL groups. The others are the relative coefficients (E'n) redistributing this energy through the different components (the sum of which being 1). The parameterization of $\mathrm{E}$ requires absolute biomass estimates of MTL, while the matrix of E'n coefficients can be estimated simply using relative day and night values integrated in the three vertical layers of the model.

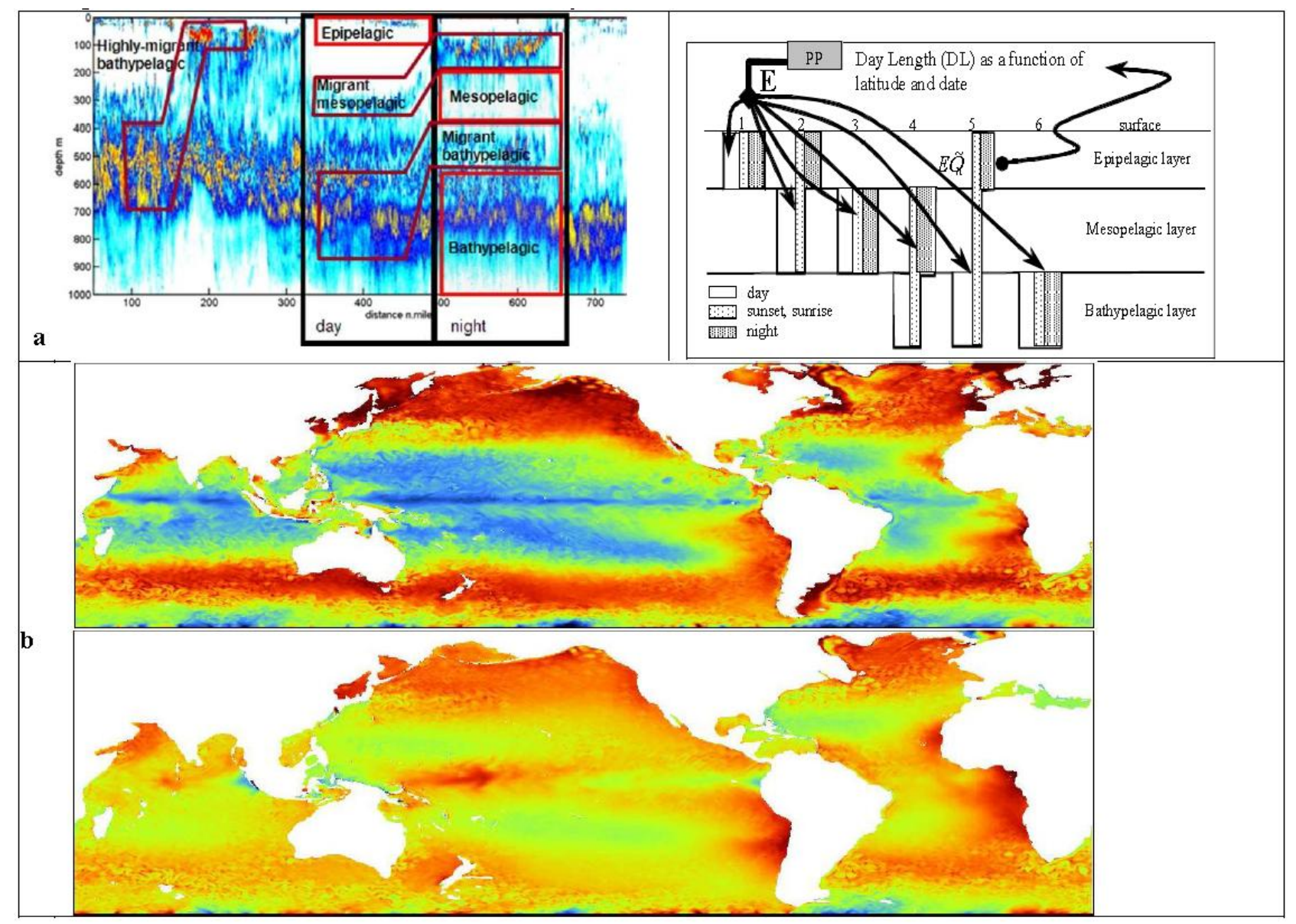

Figure 5. Mid-trophic functional groups. a) identification of MTL functional groups on acoustic echogram and conceptual model (from [3]). b) comparison between predicted biomass ( $\mathrm{g} \cdot \mathrm{m}-2)$ of epipelagic (top) and bathypelagic (bottom) mid-trophic functional groups at resolution $1 / 4^{\circ} \times 6 \mathrm{~d}$. Note the difference in biomass distribution between epipelagic and bathypelagic components due to different temperature-related turn-over time in the surface and deep layers. The color-scale from blue (lowest) to red (highest) ranges between 0-2 and 0-6 for epi-and bathypelagic groups respectively 


\section{PERSPECTIVES AND RECOMMENDATIONS}

Several programs and initiatives, as presented in the introduction, have identified a lack of information on the mid-trophic level. This gap needs to be filled in order to take advantage of recent coupled ocean circulation and biogeochemical models for predicting impact on higher trophic levels (fish, mammals, seabirds, etc.).

We believe that the results obtained by the oceanographic community using mooring, drifters and gliders have clearly demonstrated the potential for global observational approaches. The technological developments that occurred during the last decade allow us to envision now the extension of those approaches to mid-trophic components of oceanic ecosystems.

Acoustics have the right properties to observe marine life. For the same reason, cetaceans have evolved acoustic apparatus to exploit acoustic cues to detect their prey field. The reason for this success is the more favourable acoustic propagation properties of the water as opposed to optical properties. We argue that for the same reason that cetaceans are using acoustics, so should man be in its effort to observe marine life.

There are items that need to be addressed to achieve this goal, and the community should ensure a collaborative international effort to solve this important question. Our recommendations are:

1. Continue deploying observatories carrying acoustic sensors on different platforms, including ships of opportunity, stationary landers, cabled observatories, drifters etc. This will provide important data for further developing the combination techniques for models and observations.

2. Further develop the coupling between the models and observations using presently available data (from bullet point 1). This will require tight collaboration between modellers and observation technical experts. A major outcome should be to identify the most cost effective platform (stationary, drifting, or transecting).

3. Ensure technical development of low cost drifters, landers, and ship-based modules to collect acoustic data, to further support 1 and 2.

4. When these objectives (1-3) are met, a large scaled observing network containing hydro acoustic sensors with corresponding infrastructure should be developed. The network should use the most cost effective platform(s) identified in (2), including drifters, vessel of opportunities, stationary observatories etc.

\section{ACKNOWLEDGEMENTS}

NOH's contribution has been supported under the EcoFish project under the Norwegian Research Council. PL acknowledges the Groupe Mission Mercator Coriolis and the GLORYS (Global Ocean Reanalysis and Simulations) members (MERCATOR-OCEAN, INSUCNRS (Centre National de la Recherche Scientifique/ National Scientific Research Agency) and the team "DRAKKAR" (Multi-scale Ocean modelling project)) for providing the GLORYS1V1 reanalysis, and the Ocean Productivity team for providing the SeaWiFSderived primary production.

\section{REFERENCES}

1. Frank, K.T., et al. (2005). Trophic Cascades in a Formerly Cod-Dominated Ecosystem. Science, 2005. 10: p. 1621-1623.

2. Lehodey, P., I. Senina, and R. Murtugudde. (2008). A spatial ecosystem and populations dynamics model (SEAPODYM) -- Modeling of tuna and tuna-like populations. Progress in Oceanography, 2008. 78: p. 304--318.

3. Lehodey, P., R. Murtugudde, and I. Senina. (2010). Bridging the gap from ocean models to population dynamics of large marine predators: a model of mid-trophic functional groups. Progress in Oceanography, 2010. 84: 69-84.

4. Maury, O., et al. (2007). Modeling environmental effects on the size-structured energy flow through marine ecosystems. Part 1: The model. Progress in Oceanography, 2007. 74: p. 479499.

5. Richardson, A.J. and E.S. Poloczanska, (2008). Ocean Science Under-Resourced, Under Threat. Science, 2008. 320: p. 1294--1295.

6. Scholes, R.J.M., G. M. Turner W. Geller G. N. Jürgens N Larigauderie A. Muchoney D. Walther B. A. Mooney H. A, (2008). Toward a Global Biodiversity Observing System. Science, 321: p. 1044--1045.

7. Census of Marine Life (www.coml.org) is an international initiative that has a global perspective, and focuses on technology as a driver to uncover the unknown as well as describing and quantifying processes of the oceans which matches exactly the objectives of the MAAS project.

8. From the GLOBEC-IMBER Transition Task Team Report (http://www.imber.info/products/TTT_Report_F eb09.pdf) 
9. CLIOTOP (CLimate Impacts on Oceanic TOp Predators,

http://www.globec.org/index.php?id=62) is a ten year programme implemented under the international research programmes GLOBEC (2005 to 2009) and IMBER (2010 to 2014). CLIOTOP focuses on oceanic top predators within their ecosystems and is based on a worldwide comparative approach among regions, oceans and species.

10. Sund, O., (1935). Echo Sounding in Fishery Research. Nature, 1935. 135: p. 953.

11. Handegard, N.O., G. Pedersen, and O. Brix, (2006). Estimating tail-beat frequency using split-beam echosounders. ICES Journal of Marine Science, 2009. 66: p. 1252--1258.

12. Makris, N.C., et al., (2006). Fish Population and Behavior Revealed by Instantaneous Continental Shelf-Scale Imaging. Science, 2006. 311: p. 660663.

13. Sourisseau, M., Y. Simard, and F.-J. Saucier, (2008). Krill diel vertical migration fine dynamics, nocturnal overturns, and their roles for aggregation in stratified flows. Canadian Journal of Fisheries \& Aquatic Sciences, 2008. 65: p. 574--587.

14. Benoit, D., Y. Simard and L. Fortier, (2008). Hydroacoustic detection of large winter aggregations of Arctic cod (Boreogadus saida) at depth in icecovered Franklin Bay (Beaufort Sea). Journal of Geophysical Research, 2008. 113: p. 9p.

15. Korneliussen, R.J. and E. Ona, (2003). Synthetic echograms generated from the relative frequency response. ICES Journal of Marine Science, 2003. 60: p. 636-640.

16. Gunderson, D.R., (1993). Surveys of fisheries resources. 1993, New York: John Wiley \& Sons, Inc.

17. Mac Lennan, D. and E.J. Simmonds, (2005). Fisheries Acoustics. 2 ed. Fish and aquatic resources series 10. 2005, London: Chapman \& Hall.

18. Godø, O.R. and A. Totland, (1996). A stationary acoustic system for monitoring undisturbed and vessel affected fish behaviour. ICES CM 1996/B:12,

19. Godø, O.R., et al. (2005). Observatory Technology in Fish Resources Monitoring. In International Conference Underwater Acoustic Measurements: Technologies \& Results, Heraklion, Crete, Greece. 2005.
20. Trevorrow, M.V., (2005). The use of moored inverted echo sounders for monitoring mesozooplankton and fish near the ocean surface. Canadian Journal of Fisheries \& Aquatic Sciences, 2005. 62: p. 1004-1018.

21. Brierley, S. and R.A. Saunders, (2006). Use of moored acoustic instruments to measure shortterm variability in abundance of Antarctic krill. Limnology and Oceanography-Methods, 2006. 4: p. 18-29.

22. Kloser, R.J., et al., (2009). Acoustic observations of micronekton fish on the scale of an ocean basin: potential and challenges. ICES Journal of Marine Science, 2009. 66: p. 998-1006.

23. Dengler, M., et al., (2006). Deep Labrador Current and Its Variability in 1996-2005. Geophysical Research Letters, 2006. doi:10.1029/2006GL026702

24. Riser, S.C., J. Nystuen and A. Rogers, (2008). Monsoon effects in the Bay of Bengal inferred from profiling float-based measurements of wind speed and rainfall. Limnology and Oceanography, 2008. 53: p. 2080-2093.

25. Handegard, N.O., G. O.R., and P. Lehodey, (2008). Acoustic data from platforms of opportunity as fuel for ecosystem models. J. Acoust. Soc. Am. Acoustics, 2008. 123: p. 3212.

26. Kooijman, S.A.L.M., (2000). Dynamic Energy and Mass Budgets in Biological Systems. 2000: Cambridge University Press.

27. Lehodey, P., (2004). A Spatial Ecosystem And Populations Dynamics Model (SEAPODYM) for tuna and associated oceanic top-predator species: Part I - Lower and intermediate trophic components. In 17th meeting of the Standing Committee on Tuna and Billfish, Majuro, Republic of Marshall Islands. 